$\begin{array}{r}\text { Volume and Issues Obtainable at Center for Sustainability Research and Consultancy } \\ \text { Review of Politics and Public Policy in Emerging Economies } \\ \text { ISSN: 2708-3829 (E): 2708-356X } \\ \text { Volume 1: No. 2, December 2019 } \\ \text { CSRᄃ } \\ \text { Journal homepage: www.publishing.globalcsrc.org/rope } \\ \hline\end{array}$

\title{
Transforming Academic Discourse: A Case Study of International Relations as Discipline
}

\author{
${ }^{1}$ Attiq-ur-Rehman, ${ }^{2}$ Shahid Hussain Bukhari \\ ${ }^{1}$ Assistant Professor, Department of International Relations, NUML, Islamabad, Pakistan. \\ arehman@numl.edu.pk \\ ${ }^{2}$ Associate Professor, Department of International Relations, Bahauddin Zakariya University, Multan, \\ Pakistan.shahidbukhari@bzu.edu.pk
}

\begin{tabular}{|c|c|}
\hline CLE DETAILS & \multirow{13}{*}{$\begin{array}{l}\text { The study of social sciences in general and the discipline of International } \\
\text { Relations (IR) in particular, always remained the areas of less scholarly } \\
\text { significance, because the leading academic circles remained less-inclined } \\
\text { towards the non-western production of knowledge in the international } \\
\text { system. The main discussions of IR generally revolve around the western } \\
\text { discourse and approaches to knowledge. The end of the decades-long Cold } \\
\text { War and the elimination of the Soviet Union from the world politics } \\
\text { allowed the Western academic circles to influence the production of } \\
\text { knowledge in the international system. In this way, the production of } \\
\text { knowledge and the promotion of knowledge ignored the non-western } \\
\text { academic perspectives. Contrary to conventional academic patterns, there } \\
\text { is a need to realize the significance of non-western literature in academics } \\
\text { while updating the conventional academic patterns. In this scenario, this } \\
\text { paper attempts to address the questions of the production of knowledge } \\
\text { and promotion of knowledge on the basis of relative perspectives. While } \\
\text { emphasizing the non-western or non-American approaches to knowledge, } \\
\text { the central theme of the paper endeavors to highlight the importance of the } \\
\text { non-western way of looking at world nolitics. }\end{array}$} \\
\hline History & \\
\hline Revised format: November 2019 & \\
\hline Available Online: December 2019 & \\
\hline Keywords & \\
\hline Transformin & \\
\hline Relation, Discipline & \\
\hline & \\
\hline & \\
\hline & \\
\hline & \\
\hline & \\
\hline & \\
\hline
\end{tabular}

(C) 2019 The authors, under a Creative Commons AttributionNonCommercial 4.0

Corresponding author's email address: arehman@numl.edu.pk

Recommended citation: Rehman, A. U. \& Bukhari, S. H., (2019). Transforming Academic Discourse: A Case Study of International Relations as Discipline. Review of Politics and Public Policy in Emerging Economies, 1(2), 95-103

DOI: $10.26710 /$ rope.v1i2.1142

\section{Introduction}

The question of understanding the contesting attributes of the international system remained unanswered in the presence of a few western theoretical domains. The familiarity of non-western ideological domains and their presence in the world, in general, remained academically less significant. The production of knowledge and the maintenance of knowledge in the social sciences are generally considered as values of western societies which predominantly try to define the conceptual foundations of the leading academic areas. Even the understanding of the non-western feature of the international system is also defined by western scholars. So, the quest to understand the non-western cultures and their way of looking to the changing dynamics of power politics has become important for the academic community. (Karan, 2004) 
Western intellect and its popularity in the academics did not only affect the role of non-western thoughts but it also made social sciences a discipline missing international characteristics. Before initiating the central argument of the paper, the main idea of the study needs a visible clarification between western and non-western domains of the international system.

Generally, the western world refers to the areas encompassed by the countries of European and Western Hemisphere or the states from European and American continents. This definition of the west is derived from the term 'occident'. (Occident, 2020) The geographical classification of the international system contains similar arguments where the notion of the west normally pronounces American and European societies. (West, 2020) Another notion of the western world denotes the Greco-Judaic-Christian traditions which describe the religious divisions of the international society. (Lee, 2018) In contrast to the western world, the non-western civilizations denote the communities beyond European and American nations which usually includes the countries from Middle Eastern, African, Asian, and South American continents. (Karan, 2004) Here the discussion on western and non-western worlds of competing ideologies is based on capitalistic and communist formats of the international system where the American and Soviet ideas prevailed during the days of Cold War competition.

In the realist driven irresistible characteristics of the international system which is strictly constructed on the power politics principle, it is difficult to rely completely on a single description of international relations without adopting a relativist approach. The contesting ideological texts or the mind-opening features belong to alternative approaches of international system assembled mainly by the world existed beyond the west seeking appropriate attention of contemporary intellectual communities. The non-western approach of education has lost its value in the world of prevailing western beliefs. In this way, the scope of theoretical autonomy diminished in the field of IR. The overwhelming wave of western culture in academics and its worldwide promotion has degraded the importance of alternative viewpoints but the existence of various non-western prisms of viewing the international system has become an undeniable reality. Therefore, the paper is an endeavor to comprehend the growth of academic approaches based on the knowledge produced by the world besides western communities. The non-western way of analyzing the international system has become an essential element for balanced academic growth. Moreover, the principle argument in the paper focuses on the discipline of IR for examining the competition between western and non-western explanations of the international system. The paper tries to explore the relevance of alternate production of knowledge and its existence exclusively to IR which further helps the leading intellectual circles of IR in attaining a balanced and impartial understanding of academic viewpoints based on relativism.

\section{Nature of International Relations as Discipline}

The academic foundations of International Relations (IR) contain multidisciplinary or interdisciplinary values which are usually compromised. The autonomous theoretical nature of IR discipline has become a serious problem in the world of western-influenced knowledge. (Jorgensen, 2017, p. 74) As a field of study, IR generally discusses the interaction of states which decorate the multifaceted attributes of the international system. Further study of IR deals with the study of non-states actors that are smoothly functioning parallel to the sovereign states. The combination of states and non-state entities generally deals with the changing contexts of world politics and their institutional development across the globe. (Plantan, 2002) In this way, the interaction of IR as an academic discipline tries to generously study the different contesting viewpoints of opposing schools of thought irrespective of their western and nonwestern origin. The study of International Relations tries to explore logically the varying behaviors of the states along with different formats of states' interaction which is an amalgamation of conflicting paradigms. Moreover, the discipline of IR mainly focuses on intra-state and inter-state political, social, economic, strategic, and cultural developments. In this way, the working of the international system coupled with various formats of cooperation and conflict between leaders and their respective states maintains their theoretical description under the field of IR. (Ransom, 1968) An analytical survey and rational understanding for the appropriate understanding of the above-mentioned characteristics of IR 
always need a relative approach. The relative approach provides different angles to evaluate the international system.

In the world of competing ideologies and opposing government structures of the states, a practical approach to the study of IR lacks its actual documented principles. The promotion of IR discipline in the world, actually, lacks a consensus-based approach for defining different political concepts. The description of various notions in IR presents multiple explanations which are the actual spirit of this discipline. But the availability of different approaches or familiarity with contesting themes of IR has become a difficult task. In this way, the overall contents of IR reflect a distorted picture in which a single approach to study world politics based on western orientations always available. The absence of nonwester knowledge to analyze the fluctuating relations between states stops the IR intellectuals from adopting a balanced and impartial standing. (Capan, 2017) Actually, the main problem of the leading academic discourses of IR belongs to their origin and advancement. Mainly the common approaches of IR are produced and maintained by western scholars. Various scholars expressed their intellectual insight in western cultures and their states further promoted their ideologies in the world. The promotion of western ideologues and their global reach effectively influenced the foundations of IR.

The involvement of the non-western orientation of the IR in academics has become an essential need because, in the Realist driven world of competing states patterns, an appropriate understanding of the world beyond Western communities could be an unexplored dimension of knowledge. In order to pragmatically comprehend the central theme of the paper, it is necessary to develop a theoretical foundation of the study. The theoretical explanation of the paper can adequately be studied under the notion of relativism.

\section{Theoretical Understanding: The Relativism}

The homogeneity of knowledge produced and advanced by several western authors raised the significance of other ideological domains. The creation of absolutist knowledge sparked a debate in academics for studying the non-western explanations of IR. In the contemporary world, the rapidly changing geostrategic landscape of the international system made it essential to precisely explore the non-western (or Russian and Chinese) descriptions of world politics. The need to include various narratives of world politics beyond the stable western accounts highlighted the significance of a diversified knowledge in IR. A diverse approach in the IR discipline can easily be studied under the conception of relativism which views that the "truth and falsity, right and wrong, standards of reasoning, and procedures of justification are products of differing conventions and frameworks of assessment." (Stanford Encyclopedia , 2015) The actual essence of relativist notion promotes a wide range of ideas and explanations which lack consensus on a particular thing. (Stanford Encyclopedia , 2015) In other words, it is widely considered to be a phenomenon that is dependent on other factors or it alters its position due to its dependency on the independent variable. The independent variable could be culture, history, belief, norms, language, etc. (Stanford Encyclopedia , 2015) In short, the advocators of relativism in academics believe that the "one thing is relative to some particular frameworks", and it prefers to consider equally valid every available viewpoint of a particular thing. (Westacott, 2018) The relativists maintain their positions in response to the absolute explanations of different objects. The primary conception of relativism denies the existence of a single or universal explanation of various ideas. (Vallicella, 1984, p. 453) By rejecting the absolutist notion of developing the knowledge, the advocators of relativism accept the contesting and varying explanations of ideas. (Grady, 2014, p. 89) In this way, the philosophy of relativism allows people to maintain their differing positions from each other or conflicting with any self-accurate description of the world. (Darmstadter, 2016) The application of relativism in the field of IR believes in varying approaches to understanding a particular idea. The traditional theoretical trend in IR prefers to oppose the principle of relativism, and the presence of western conventional wisdom in IR weakened the interdisciplinary nature of this discipline. In order to rationally comprehend the conceptually varying and technically opposing ideas in IR originated from diverse backgrounds, the proponents of relativism favor the academic norm of theoretical autonomy. (Guilhot, 2011, p. 139) 


\section{The Post Cold Academic Monopoly}

The unforgettable decades-long period of Soviet-American confrontation under the atrocious shadows of the Cold War marked an unending competition between Moscow and Washington DC. The emergence of Mikhail Gorbachev in the Soviet Union and his reorientation of Moscow's strategic position in the world politics dismantled Union of Soviet Socialist Republics in 1991. (The Economist, 2017) The dissolution of the Soviet Union let the American policymakers to declare the end of forty-year antagonistic designs of the Cold War. The leading state officials of the Bush administration termed the converting of Soviet Union into the Russian Federation as the defeat of Moscow. No doubt, the end of Communist rule over the fifteen republics of the Soviet Union provided sufficient chances to the United States for the promotion of American values across the globe but the strategic clash between White House and Kremlin remained an undeniable reality of the international system. The subsequent political developments in the great power politics witnessed the continuation of Washington-Moscow competition in the international system. (Singer, 1999) The post-Cold War phase of world politics observed various changes in favor of the United States. A wide range of scholarly engagements from different parts of the world supported the unchallenging role of Washington in international affairs. The advancement of American supported unilateral attributes in the brief Soviet-less period of world politics was admired by western theoretical domains. The conceptual features of western scholars did not only accept the concepts of New World Order of the Bush in the transitionary period of world politics but they acknowledged the American perceived unilateral structure of international relations under Washington's leadership. (Levy, 1996, p. 255) The prevalence of Bush's coined term of New World Order in the international system defined various features of the international system under American leadership. The fundamental purpose of the New World Order was to govern the post-Soviet period according to American desired ways while enhancing Washington's engagements across the globe. Another considerable development in the form of The End of History and the Last Man further supported the notion of American supremacy in the world. (Hughes, 2012, pp. 6-7) It was an American way of looking at the international system which was constituted by Francis Fukuyama. He attempted to predict the international order under American values. The broader vision of his ideas advocated the widespread promotion of liberal democracies and capitalistbased market economies. (Hughes, 2012) Fukuyama advocated the dominance of the west in world politics. He says the west has started enjoying indeterminate satisfaction because the western world has reached the end of history. The promotion of western ideas and their acceptance has reached every corner of the world. (Salem, 2018) In this way, Fukuyama unrealistically selected the western political attributes cemented solely in American values as the last format of human history. Apparently, it was an admiration of Washington's increasing role in world politics in the absence of potential counterbalancing forces. Apart from Fukuyama, several other political scientists invested their intellectual capacities in lionizing the Soviet-less international system under American dominance.

The leading commentators of international relations advocating the American expanding values in the world were actually influenced by Washington which heavily affected their pragmatic approach of analyzing world politics. Theoretical versions of the international system were mainly ignored by the American influenced academic communities of the West. A brief period of crisis in Moscow during the two regimes of Mikhail Gorbachev and Boris Yeltsin gave an appropriate place to the United States in world politics. (Smyth, 2018) An advancing version of US activism was challenged before the Realist driven standards of the international system where the status quo can temporarily survive. The undeniable principles of power politics in the international system rapidly started to underestimate Washington's way of managing international relations. In short, the end of the Cold War was a geographical incident instead of a termination of the ideological American-Russian conflict. (Marcus, 2018) The temporary demise of Russian status in world politics advanced the western view of the international system across the globe.

\section{The Paradigm Shift}

The undeniable realities of the twenty-first century and the emergence of non-traditional security threats under the globalized formats of world politics surprisingly changed the course of human history. The 
transnational nature of security threats in the new world did not only alter the strategic outlook of international relations but it also undermined the traditional approaches of states for managing their positions in world politics. (Swaine, 2011, p. 256) Such characteristics of changing the international system hampered Washington's perception about ongoing power politics which was exactingly inherited in the Cold War era. The American strategic thinking developed during the confrontational period of the Cold War lost its significance before the crisis of the twenty-first century. In the wake of the new century, the tragic incident of 9/11 acutely shocked the leading national security architectures of Washington. The conventional national security mechanism for addressing the traditional security threats emanating from the rival gathering of communist leaders became an outdated element for Washington. (Bolton, 2008, p. 170) In reaction to the terrorist attacks of September 2011, the security pundits of the Bush administration decided to initiate a global war against terrorism. The initiation of war on terror was perceived to be another factor that could effectively help Washington in maintaining its global superpower status because the American security establishment launched a global campaign to counter-terrorism. (Holloway, 2008, p. 4) No doubt, the US-led global counter-terror coalition internationally considered another way of dominating the international system, but it intensified American global engagement in world affairs. In this way, the world of new realities demanded the Washington based security establishment of the United States to change its traditional prism of analyzing the international system. (Holloway, 2008, p. 4) In order to achieve the main objectives of the counter-terror alliance, Washington preferred to prevent potential threats to the American position in the world. The divisions of states between Axis of Evil and Rogue States apparently showed the United States' commitment to managing the international relations, but it dramatically deepened the American role in the world politics while rising the role of counterbalancing forces. The widespread US engagement in diverse regions raised an unbearable wave of anti-Americanism around the globe. An overwhelming global tendency of anti-American thinking unpredictably mushroomed globally which consistently fabricated an international environment of American antipathetic sentiments in the world. Washington's presence in the various countries under the broader anti-terror alliance was being considered to be a probable situation that could cause an outbreak of war. Such sentiments cultivated an international tendency of anti-American thoughts. The majority of Muslim countries started to reflect a zenith level of anti-American thinking which was the result of Washington's greater support of Israel. Moreover, the Muslim countries under the war on terror started to raise their concern against American anti-Muslim policies. In addition to its support for Tel Aviv's belligerent behavior against Arab states, the American invasion of Iraq for the search of Weapons of Mass Destruction and the presence of its forces in Afghanistan added fuel into the fire. (Miles, 2013, pp. 1-2) Therefore, the wars in Iraq and Afghanistan caused irresolvable damage to both countries while posing a serious question on American initiated war against terrorism. Moreover, the deteriorating security situation in the Middle East under the rubric of the Arab Spring further attached a stigma to Washington's global image.

In order to dominate international nuclear politics, the Washington-based advocators of global arms control efforts always supported the global non-proliferation regime. Effective implementation of the international nuclear non-proliferation regime by supervising the states' nuclear ambitions became another American way of increasing its global engagement. The American role in global nuclear politics reveals a dichotic version of Washington's non-proliferation policies which are mainly carrying contradictory behaviors. Despite of encouraging the states for remaining loyal to the international nonproliferation regime, the leading state authorities form Washington are busy in the signing of nuclear deals with different allies and close strategic partners. (Einhorn, 2017) Moreover, critically evaluating the nuclear and missile programs of a few countries also reflect an American behavior lacking impartial principles and increasing White House's role in the international system. An international nonproliferation policy deficient to maintain a balanced worldwide approach has seriously questioned the United States policies about nuclear non-proliferation.

Additionally, the emergence of counterbalancing forces in the form of Russia and China has developed a different scenario in which the leading state authorities from Washington are perplexingly unable to 
maintain the supremacy of the United States. Presently, an awful wave of ferocious political changes in the Middle East mainly became an unacceptable challenge for the United States. American self-perception of its global dominating status has increased Washington's global engagement on one hand. On the other hand, it has posed a number of serious threats to the United States. In this way, the convention wisdom of the United States for managing international relations after the disappearance of the Soviet Union has become an outdated feature for Washington. No doubt, the disappearance of Sovietism from the face of the earth has provided excruciating confidence to the United States, but the architectures of national security strategy from Washington proved inefficient in stabilizing the American supremacy.

In this way, the western way of analyzing the international system was a tool for maintaining Americanoriented western dominance in world politics. A combination of various security doctrines inherited in counter-terrorism and counter-proliferation campaigns of the United States launched an international alliance of western powers under American leadership which subjugated the role of non-western approaches of managing global affairs. In order to analyze a disturbing equation of western and nonwestern thoughts in world politics, it is essential to comprehend the main problem between both approaches and their worldwide advancements.

\section{The Academic Puzzle}

In the presence of unending conflict between western and non-western approaches to study the IR discipline, the interdisciplinary nature of this academic field has been significantly compromised. In the contemporary age of globalization, the multidimensional knowledge inherited in different viewpoints has become an indispensable need of academics in which the availability of diverse approaches can broaden the scope of education. In the field of IR, the familiarity with different approaches can potentially let its intellectuals to explore the further new dimensions of subjects under investigation. The intellectual rivalry between different western and non-western ideologues is an irrefutable issue because the description of various political developments and their academic classification in the international system leaves the intellectual community of both formats of the world in two opposing blocs. Both ways of analyzing world politics generally encompass not only different viewpoints but they have developed opposite ways of perceiving the world politics. In this way, the intellectual attempts to build a consensus-based broader generalization of international affairs remained merely a difficult task because the two-sided scholars are strict to their opposite position.

- The western approaches are largely produced massively across the globe. The production of knowledge under western umbrella further advanced by the western state authorities. Instead of restricting the information to specific countries, the western ways of studying the IR heavily translated in several different languages which ensured the global reach of western academics. Unlike non-western approaches of examining international affairs in a specific way and further keeping them restricted to specific areas, the western scholars tried to explore the world by expressing their thoughts independently. The combination of the language barrier and the government strict policies on supervising the production of knowledge in the non-western areas unexpectedly gave rise to western approaches of IR.

- The political circumstances played a vital role in effecting the non-western academic campaign in the world. The western community working in the IR discipline usually belongs to the powerful states that remained dominating power in the international system. Evidently, the end of two world wars coupled with the end of decades-long Soviet-United States conflict granted victory to the western powers, and the western states heavily considered themselves the gravitational point of world politics unlike non-western bloc of states. Such political developments did not only let the western communities dominate international organizations (like the United Nations) but it also permitted the western states to suppress the intellectual voices rising from non-western countries. 
- The quest to comprehend the non-western cultures along with the political orientations of the world beyond western communities remained merely a theoretical aspiration of IR scholars. In the presence of the above-mentioned circumstances, the non-western description of knowledge remained an unexplored dimension of academics. Regrettably, the political, culture, and social description of the non-western world is also coming from western communities. The western intellectual circles are actively engaged in explaining the various characteristics of the nonwestern world which is indirectly becoming a non-western narrative building by the west.

The abovementioned factors diminished the actual spirit of IR in academics because the role of abovediscussed obstacles damaged the relativist way of analyzing the international system of an ending theoretical competition. The knowledge about different but relative perspectives in world politics reveals several competing political practices across the globe which eventually result in various theoretical disagreements. In the presence of a consensus-based and universally acceptable visualization of various political developments, the persuasion of a single explanation of the international system fracture the theoretical autonomy in IR. (Esikot, 2012)

\section{The Way Forward}

The colonial foundation in the discipline of IR is the main problem that lacks an autonomous status. The essential need is to decolonize the discipline of IR from western influence because an independent status of the IR field could be helpful in broadening its scope. The process of decolonization cannot easily be adopted in the existence of a robust western influence. A multilevel approach is needed to liberate the IR from western influence because a multidimensional approach could be helping in generating a complete non-western way of understanding the international system. Such an approach will be further supportive in building a complete non-western narrative by studying the non-western theoretical domains. In this way, the non-western production of knowledge can provide a non-traditional version of IR in which mainly the Russian and Chinese versions of studying international relations could be involved. The need to reorganize the intellectual foundations of IR by considering the importance of alternative approaches constructed in the non-western world is seeking appropriate attentions of the leading academicians. An adequate measure for the maintenance of such an approach will further help in including the technically different and theoretically contrasting ideologies in the mainstream scholarship of IR. The adaptation of such an approach will further help in constructing a multicultural environment of cross-political representation of various schools of thought rising from the non-western world particularly. (Singer M. , 1964) Moreover, the political attributes of the Korean peninsula along with the Latin American way of defining the international system is another missing dimension of IR which should be appropriately considered in IR. The unfamiliar knowledge of international political structure from the states of the third world needs to be observed as an essential part of the IR discipline. The inclusion of such attributes in the field of International Relations cannot be considered an attack on western values, but it should more appropriately be spelled out as an attempt of ensuring the balanced and impartial fundamentals of IR. Moreover, a comprehensive way of studying the non-western aspects of analyzing world politics could not be measured as an attempt to neglecting the significance of western knowledge in IR.

\section{Conclusion}

The central theme of the paper revolves around the significance of non-western approaches to the study of world politics in general and International Relations in particular. It should be considered an attempt to reveal the role of alternate dimensions or non-American ways of looking at the world. The increasing familiarity with the non-western literature for the study of international relations and its emergence in the international system shall strengthen the scope of IR by including its role in global affairs. In this way, a comparative academic approach to analyze the subjects related to the discipline of IR on the basis of competitive viewpoints is the fundamental purpose. The fundamental objective of the paper is to introduce a robust international approach to study the world under the broader dimension of IR which will not only ensure the hybrid description of IR but will also develop a comparative approach in IR. The adoption of such an approach will lead the main scholarship of IR toward a greater recolonization of other 
approaches of IR which are less popular but more important to study.

\section{References}

Bolton, M. K. (2008). U.S. National Security and Foreign Policymaking After 9/11: Present at the ReCreation. Plymouth: Rowman \& Littlefield Publishers.

Capan, Z. G. (2017). Decolonizing International Relations. Third World Quarterly, 38(01), 09.

Darmstadter, H. (2016). Relativism Defended. Cogent Arts \& Humanities, 03(01).

Einhorn, R. (2017). Non-Proliferation Challenges Facing the Trump Administration. Brookings. Retrieved April 30, 2018, from https://www.brookings.edu/research/non-proliferation-challengesfacing-the-trump-administration/

Esikot, I. F. (2012). Globalization Versus Relativism: The Imperative of a Universal Ethics. Journal of Politics and Law, 5(4), 131.

Grady, P. O. (2014). Relativism. Routledge.

Guilhot, N. (2011). The Invention of International Relations Theory: Realism, The Rockefeller Foundation, and the 1954 Conference on Theory . New York: Columbia University Press.

Holloway, D. (2008). 9/11 and the War on Terror. Edinburgh: Edinburgh University Press.

Hughes, C. (2012). Liberal Democracy as the End of History: Fukuyama and Postmodern Challenges.

New York: Routledge.

Jorgensen, K. A. (2017). Reappraising European IR Theoretical Traditions. Palgrave Macmillan.

Karan, P. P. (2004). The Non-Western World: Environment, Development, and Human Rights . Routledge.

Lee, R. (2018). Seven Principles of the Judeo-Christian Ethics. Retrieved April 24, 2018, from Sermon Central: $\quad$ https://www.sermoncentral.com/content/Richard-Lee-7-Principles-Judeo-Christian-

Ethic?ac=true \&csplit $=9060$

Levy, P. B. (1996). Encyclopedia of the Regan-Bush Years. Connecticut: Greenwood Press.

Marcus, J. (2018, April 01). Russia V the West: Is This a New Cold War. Retrieved April 28, 2018, from http://www.bbc.com/news/world-europe-43581449

Miles, A. (2013). US Foreign Policy and the Rogue State Doctrine. New York: Routledge.

Occident. (2020, March 15). Retrieved March 15, 2020, from Cambridge Dictionary: https://dictionary.cambridge.org/dictionary/english/occident

Plantan, F. (2002). Multidisciplinary Approaches, Disciplinary Boundaries, and Institutional Responses in American Higher Education: A History of International Relations as a Field of Study. Pennsylvania: University of Pennsylvania. Retrieved April 26, 2018, from https://repository.upenn.edu/dissertations/AAI3043939/

Ransom, H. H. (1968, May). International Relations. The Journal of Politics, 30(02), 345-346.

Salem, P. E. (2018). A Critique of Western Conflict Resolution from a Non-Western Perspective. Retrieved April 26, 2018, from http://www.ciel.usj.edu.lb/docs/CR/p_salem.pdf

Singer, J. D. (1999). Prediction, Explanation, and the Soviet Exist from the Cold War,. The International Journal of Peace Studies, 4(2). Retrieved April 26, 2018, from http://www.gmu.edu/programs/icar/ijps/vol4_2/singer.htm

Singer, M. (1964). The Social Sciences in Non-Western Studies. The Annals of the American Academy of Political Science, 43-44.

Smyth, R. (2018, March 30). Is the Growing Russia Crisis Another Cold War Conflict? Nyet. The Conversation. Retrieved April 26, 2018, from http://theconversation.com/is-the-growing-russiacrisis-another-cold-war-conflict-nyet-94093

Stanford Encyclopedia . (2015, September 11). Relativism. Retrieved April 26, 2018, from Stanford Encyclopedia of Philosophy: https://plato.stanford.edu/entries/relativism/

Swaine, M. D. (2011). America's Challenge: Engaging a Rising China in the Twenty-First Century. Washington: Carnegie Endowment for International Peace.

The Economist. (2017, August 31). How Mikhail Gorbachev Ended the Cold War. The Economist. Retrieved April 26, 2018, from https://www.economist.com/news/books-and-arts/21727880peasant-boy-turned-communist-party-boss-who-liberated-his-people-70-years-lies 
Vallicella, W. F. (1984, July). Relativism, Truth and the Symmetry Thesis. The Monist, 67(3).

West. (2020, March 15). Retrieved March 15, 2020, from Cambridge Dictionary: https://dictionary.cambridge.org/dictionary/english/west

Westacott, E. (2018, April 26). Relativism, (accessed on April 26, 2018). Retrieved April 26, 2018, from Internet Encyclopedia of Philosophy: http://www.iep.utm.edu/relativi/ 